\title{
The Soundtrack for Alexei Balabanov's Movie Morphine": Cruel Romance with the Passing Epoch
}

\author{
Daria Zhurkova \\ Department of Mass media art's studies \\ State Institute for Art Studies \\ Moscow, Russia \\ E-mail: jdacha@mail.ru
}

\begin{abstract}
The article studies the specific features of interaction between music, plot and a recreated epoch in Alexei Balabanov's movie "Morphine". The author analyzes in detail the meanings, which the old-time romances playing in the background bring to the cine-narrative. Firstly, we can see direct plot parallels between cinematic and musical content, for example, the leitmotif of drug addiction of the protagonist. Secondly, there are hidden reasons for the deliberate mismatch of the nature of music and the unfolding events in the film. The author comes to the conclusion that the refined, broken poetics of cruel romances turns out to be consonant with both the prerevolutionary era in Russia and the fatal passion of the protagonist for morphine.
\end{abstract}

Keywords-music; cinema; Balabanov; Morphine; drug addiction; Aleksander Vertinsky; cruel romance; lullaby; tango; convict song

\section{INTRODUCTION}

Music, along with the motifs of the city, war and cinema, is one of the main components of Alexei Balabanov's artistic thinking, extremely authoritative and provocative. A special director's instinct for music, largely intuitive, based on his own musical preferences and erudition, but always accurately falling into the "picture" - a unique case for both domestic and world cinema. When it comes to scrupulousness and meaningful use of music, Balabanov can be compared with Tarkovsky, as well ashis foreign colleagues Fellini, Kubrick and Tarantino. All these directors have music that is inseparable from the artistic conception, music that is etched deep inside the viewers and serves meaning-creating rather than merely design purposes.

In the movie "Morphine" (2008), the director does not change his main principle and again takes popular music, "cooked" by the era in which the film's events occur. Another point is that the time distance played an interesting role in the perception of the musical design of the film. On the one hand, Balabanov took music which was really popular at the beginning of the twentieth century. On the other hand, that music had an extremely mixed reputation in the era of its release, and even more afterwards. The genre of urban romance, especially "gypsy" and "cruel" romance was often considered banal, vulgar and tasteless. Yet, Balabanov uses this music as a finely tuned barometer, fixing the internal differences of the re-created era. Thus, the director for the first time in his practice overcomes the conflict between "correct" and "false", genuine and "ostentatious" music, which in his previous films was most clearly manifested in contrasting rock and pop. In "Morphine", one can hear pop of that time, the music which turns out to be not just a "true witness", but an anomaly continuum, simply speaking - the air of that era.

In this article, I will first outline the conceptual parallels between the genre of urban romance, the era of the film, and the character of its protagonist. Next, I will trace the semantic intersections between the lyrics of theromances played and the fate of the main character of the film, through the theme of fatal passion in particular. After that, special attention will be paid to the issue of external mismatch of the music nature and the events unfolding on the screen. Throughout the study, I will put emphasis on the following issues: 1) the nature of the music, 2) the lyrics of the romances, 3) the atmosphere of the pre-revolutionary era, and 4) the fate of the protagonist of the film.

\section{PeCUliarities of EPOCH, Music AND Plot INTERACTION IN THE MOVIE}

In "Morphine", in addition to specific plot parallels between cinematic and musical content, which will be discussed below, there are also conceptual parallels. The first one is the scope of the view. Just like the plot of the film with great historical events given through the prism of the person, the romances playing in the movie concentrate on the inner experiences of their characters. The second conceptual parallel follows on from the first. Despite the fact that both the events described in the film and the romance scenes seem to be a special case, the entire epoch can be seen through them. It would seem that the music of urban romances with their stories about fatal love has no direct relation to the prerevolutionary atmosphere. However, it turns out that the music, like nothing else, reflects its time - the time of total breakdown, a sense of hopelessness and despair of a man who cannot overcome his terrible ordeal. Yet, the question of who is the root cause of the misfortunes - the person himself or the era he is bound to live in - remains open.

Thus, the genre of urban romance with its intimacy and exaltation of senses at the same time is commensurate with 
the story that is told in the film. However, there is one more conceptual parallel that lies between urban romance as a genre and mute cinematography, also playing its role in "Morphine". Both of the mare the creations of urban culture spontaneously is becoming mass phenomena at the beginning of the twentieth century. Silent cinema, as well as cafe music, took their audience to the world of illusions, made it possible to disconnect from acute social problems, helped "to drown out the anxiety hanging in the air, to get distracted from the challenges posed by life" [4]. No wonder, these two kinds of art even met on the same platform. According to Vladimir Babenko, "in 1910-1914 in cinema halls of large Russian cities, the intervals between the shows were filled with divertissements featuring performers of rhymes, gypsy romances, convict songs, various parodies, and farcical scenes "[5]. Finally, it is important to mention the piano music being an invariable attribute of both romance lyrics and the first cinema sessions.

Meanwhile, the director remains true to his principle emphasizing the intrusive discrepancy between the events taking place in the film and the content of the songs. More precisely, Balabanov draws a link between the visual-plot series and music at a more subtle, deeper level.

At first glance, broken, pampered, far from pressing problems music we hear in the film, is a striking contrast to the unattractive, heavy and repulsive way of life that surrounds the film's main character, Dr. Polyakov (Leonid Bichevin). A vivid example here is a famous tango "Magnolia" by Alexander Vertinsky, which plays for the first time when Polyakov and his medical assistant (Andrei Panin) walk in the hospital courtyard. In twilight, the characters make their way from one wooden house to another along narrow bridges, laid through dirty snowdrifts. It is when we can hear brisk chords and a languid melody going: "In banana-lemon Singapore, in storms ..." For the protagonist, who now and then starts a gramophone with records that he got from a previous doctor, this alternative musical reality turns out to be akin to what he will later create with the help of morphine. This way Balabanov directly conducts his favorite comparison of music and drug. ${ }^{1}$

Even though most of the music playing in the film belongs to one era, even to one genre, we should take a closer look at individual compositions, since practically each of them carries important subtexts that significantly expand the basic semantic field. It is important how the original content of a romance relates to the specific episode in which

The motif of music, as a means of "disconnection" from the horrors of the surrounding reality, can be traced in almost all of Balabanov's films. For instance, in the director's debut feature film "Happy Days" (1991), the main character always carries along a music box to turn to it in moments of despair. Danila Bagrov in both of the films "Brother" (1997) and "Brother 2" (2000) constantly listens to music in his player. Another example is the Siamese twins in the movie "About freaks and people" (1998). The more terrible the torture becomes, the louder they sing "The monotonously thundering bell". Finally, the motif reaches its apotheosis in the film "Cargo 200" (2007), when the Soviet music hits, heard on TV, become an indispensable "anesthetic" for the maniac policeman's mother. Loud cheerful music, along with vodka, allows her kind of ignore the atrocities unfolding in their apartment. it is used, as well as to the figurative and plot structure of the entire film narration.

\section{Music LEITMOTIFs OF DRUG ADDICTION}

In the very first scene of the film, when Dr. Polyakov is met at the district station to be taken to his new place of work, "Snow Lullaby" by Alexander Vertinsky is playing:

Sleep, my dear boy, for the window cold,

There drifts from our front porch.

I am a lover of my mom's, and she had a husband

The old, white-haired thy father

Neither the story of the romance - the confession of the mother's lover to her young son, nor the gloomy nature of the music, with all its melodramatic intonations (turns, retardations, expressive cadence idioms) formally do not correspond to the situation of arrival, to the starting with a clean slate story, and to the sunny weather in the frame. This is not an illustration of what is happening in the episode, but a song foreshadowing the whole story.

The character of the romance turns to the child as to the most helpless and at the same time innocent observer of the love triangle. Such a technique helps to see the age-old story from a new angle, undoubtedly adding to its volume, originality and mystery. The listener, whether willingly or not, raises multiple questions that do not find answers in the immediate story collision. Yet, due to the nature of the music, a sense of doom, despair, and injustice prevails.

In this romance, the priority of Balabanov is the image of a small, defenseless boy, who the protagonist of the film is apparently equated to. Moreover, if we draw symbolic parallels further, then the "boy's" mother appears to be his life, and the "old man" - the historical time. The lover, on whose behalf the song is performed, is morphine, and it is not by accident that the words "Sleep, my dear boy, for the window cold" sound as the leitmotif. The comparison of cold (external turbulent events) and home (a place where you can find peace and rest) begins to play a special role in this context. This is the effect of comfort, "lulling", and detachment that the protagonist of the film is looking for in morphine. Thus, the song, playing in the very first episode, represents the idea of the whole film in a concentrated metaphorical form, and becomes an encrypted program of the upcoming dramatic conflict.

It is in the middle of the film when "Snow Lullaby" appears for the second time, directly visualized. After another injection of morphine, Dr. Polyakov looks out of the window of his bedroom into the yard to see the night and drifts. Such a "literal" match of the song and the video, however, does not cancel the power of its symbolic meaning. By that moment, it becomes obvious that the "boy" is not likely to "wake up".

The figurative worlds of romances that come out from the gramophone become a waking dream for the main character. Probably the brightest of them is the already 
mentioned tango "Magnolia" by Vertinsky, so we should dwell more on it.

Vertinsky's melodramatic story ("Yvette, you are crying/ For our song is dying") is peppered with an element of irony in relation to both the sophistication of the scenery painting ("A parrot shouts, frightening/You're standing still and sighing"), and the love sufferings of the character ("The tiger skin you sleep on is luxurious/ Amid the monkeys' screams."). The character does not seem to empathize with the feelings of his counterpart. In his approach, there is disengagement and an ironic smile, amplified by the nature of the music. A decisive, biting tango deals with sentiments with just one stroke of a dotted rhythm.

Despite the obvious anachronism, Balabanov apparently included this composition in the film because a visually bright, literally visible image of another reality - the reality far from winter, Russia, medical and domestic physiology that surrounded the main character - was extremely important for the director. In this tango, like in the Soviet songs of "Cargo 200" (2007), an unattainable, fantasy picture of the world comes into play. However, while in "Cargo200" such a picture of the world was implicitly false, deceitful and covering lawlessness, in "Morphine" the fantasy world is vitally necessary; it is a disastrous, but indispensable means of disconnecting from the hardships of everyday life and dramatic historical events. In this case, music is released from responsibility for what is happening; it is nothing more than an anesthetic, and everyone decides for themselves whether to take it or not.

In addition to the described above "Snow Lullaby", Balabanov introduces into the soundtrack of the film two more songs that become the leitmotifs of Dr. Polyakov's drug dependence. In the lyrics of the first of these songs - "I shall not forget that dark night " - there is no hint of drugs, but there is a vivid description of a fatal passion. In terms of both music and image, this composition uses a standard set of cruel romance attributes. It is based on an extremely schematic melodramatic story, relying on the three basic images - night, love, grave.

Exaltation of feelings, fatal passion and threats are a typical range of images represented in this cruel romance. However, in the context of the film, it is perceived not only as the backdrop of the era, but also as an ominous prediction of the character's future. The story of the romance is rethought to be not love for a woman, but rather an addiction to morphine. It is no coincidence that this music becomes the leitmotif of the first "date" with the drug. It plays for the first time when doctor Polyakov first takes morphine, and we hear it later, when Anna Nikolayevna (Ingeborga Dapkunaite) - the nurse and mistress of the protagonist - makes her first injection. It all occurs at night and the words: "I shall not forget that night, / And you will never forget it" - sound like the characters' oath, which makes Polyakov and Anna Mikhailovna guardians of one secret - their passion to morphine, rather than to each other.

Another musical leitmotif of the film is a song by Alexander Vertinsky "Cocainette", and its story directly echoes the fate of Dr. Polyakov:
What are you crying about, my pathetic, abandoned, and silly Miss

Crucified by cocaine on a drizzling Moscow boulevard?

Your delicate skinny neck is barely wrapped in an old neckpiece.

Just like you, it's worn-out, wet, amusing, and a discard.

The character in the song looks at his counterpart with compassion. His constant "child" when addressing her emphasizes the defenselessness, immaturity of the character, who will die without having time to grow up and become an adult woman. Another epithet - "crucified by cocaine " alludes to her holy, blessed status. It implies that the character is not the one to blame for her fatal passion. It is time that leaves her no chance, and then sneers at human weakness. The song rushes in the whirlwind of a mad waltz. The fast tempo does not give you an opportunity to feel deep compassion for the "pathetic, abandoned, and silly miss", so you can only glance at her, while life rushes on leaving the weak on the sidelines.

This song is extremely symptomatic in the context of the film. Along with the direct storyline related to drug addiction, it captures well merciless time running. The vocal version of the song plays once only performed by Tanechka, a seemingly appealing daughter of the landowner, which is seen as a kind of escapade of the female character.

According to the story of the film, Tanechka appears to follow social niceties and complies with the guests' request for playing something. However, her choice of frivolous café music expresses the character's protest to the society as well as to her treacly image of an upstanding citizen in their eyes. In this whirlwind of sounds and meanings, her bold, rebellious, defiant to social niceties nature breaks through. This seemingly traditional act of home music playing can be considered to be the cry of the character's sole, when she enjoys the opportunity to speak out formally without going beyond the pale.

Apart from the above-mentioned scene, "Cocainette" constantly plays throughout the film as piano music, accompanying various situations of the characters' day to day fussing and pacing. On the one hand, this music, with its overwhelming energy, adds the sense of dynamism and rapidly changing events in the film. On the other hand, there is a reference to a ballroom pianist's play in the silent cinema, which creates an effect of detachment and reminds the viewers that all they see on the screen is just an illusory world of the cinema.

\section{PRINCIPLE OF DELIBERATE INCONGRUENCE}

In general, optimistic or at least not tragic music is not typical of "Morphine". Music, along with the relaxing change of episodes interspersed with blackouts and titles for a silent cinema, together with a sense of constant "underillumination" of the frame, increase the effect of oppressive viscidity in the narrative. Even if in one of the components (the story, music or the frame) one can get a fleeting glimpse 
of the light, then other components will always prevent one from living the moments of happiness to the fullest.

For instance, in one of the episodes Dr. Polyakov takes a morning bath in a good mood. Anna Nikolayevna, the woman he is clearly attracted to, comes to see him. However, the background to this generally cheerful episode is the romance "Swan Song" by Mary Puare. A low female voice from the recording is hysterical, barely legible, singing at a very slow pace a song going: " I feel sad, if you can understand/ My trusting and tender soul / Come and blame me / On my strangely rebellious fate ".A seeming well-being in the scene is distracted by the mood of the quietly playing music, transmitting a feeling of decay and impending doom, which is in the air.

There are also reverse illustrations, when cheerful music is placed in such a context that it loses a fair share of its original optimism. Take for example a famous P. Bulakhov's romance "Troika", lyrics by Vyazemsky. It is quite up-tempo, with bright encouraging exclamations and a happy story depicting a long-awaited meeting of lovers. This romance is perceived as a rare (in the context of the whole soundtrack) oasis of seemingly achievable happiness. Yet, it comes into play in the scene of Dr. Polyakov's withdrawal. A constantly repeating dashing verse ("Rushing, rushing, rushing to her / Rushing to his beloved") gets too intrusive and inappropriately enthusiastic. Moreover, Balabanov adds to the feeling using the technique of a broken record. The annoying looping background music sounds rhyming with the insistent need for a new dose of morphine. The fact that Dr. Polyakov has entered a vicious circle because of his addiction finds an eloquent sound expression. The character is afraid to admit it to himself, but music does it for him.

The final and very symbolic chord in the dramatic turmoil of the character, as well as the entire era, is the final scene of the film. While being treated for morphine addiction, Dr. Polyakov escapes from a psychiatric hospital and finds himself watching a film in the movies. Sitting amidst a crowd of laughing viewers, the character injects himself with morphine again. After that he joins the audience laughing, as if immerging himself in the performance shown on the screen, but a minute later he shoots himself with a pistol.

The whole episode is accompanied by brisk piano music, as if performed by a ballroom pianist during a movie show. Balabanov traditionally reinforces the drama of the situation by the glaring mismatch between vigorous, marching music and the desperate act that the protagonist is preparing to perform. However, following the same tradition, the director builds deep symbolic parallels between musical and cinematic storylines.

There comes a piano version of a convict song with a speaking name "I'm a dead boy", known from the middle of the 19th century. If you are familiar with the lyrics of the song, it becomes obvious that it is closely related to the fate of Dr. Polyakov. "I'm a dead boy" is a concise summary of all that has happened, which is also perceived as an echo of the very first song in the film - "Snow Lullaby", in which the character lulled the boy too. Yet, the image of Dr. Polyakov has nothing to do with either the origin of this music (in fact, it is a proto Russian gangster song), or the character's "track record", including murders and ordeals ("I killed my father, I killed my mother, / I drowned my younger sister in the sea ... Goodbye, Odessa city, goodbye, our quarantine, / We're sent to Sakhalin Island").

A scrappy nature of the music, seemingly contrary to the content of the lyrics, can be explained by the views of the character. The lines of the chorus ("I am a dead boy, / Dead forever, / and year after year / my life is passing me by"), together with the nature of the music, suggest that the character takes his social and moral "death" as normal. Such a scenario is quite expected, it even feels comfortable for him. The character in the song voluntarily renounces freedom and condemns himself to eternal hard labor. In a broader sense, such a life strategy - to block all your escape routes, strip out hope to live in despair and count the years passing by- is very typical of Russian people. However, Polyakov is not an average person, he is an intellectual, who is supposed to fight, internally resist the era, the circumstances, but not dissolve in them. Nevertheless, he "drowns" himself in morphine, which resembles the folksy relatives' murder.

\section{CONCLUSION}

So, in "Morphine" Balabanov exploits the idea of music used as a drug, bringing it in line with a real addiction. Dr. Polyakov urgently needs to switch from a painful, physically complex and physiologically repulsive reality. The main character's urge to constantly turn on a gramophone is an expression of his painful dependence on the world of illusions, which he enters through either music or morphine.

It might seem that Balabanov repeats the same motif music as a drug, which he implicitly used in both of his other films "Brother" and "Brother 2", as well as in "Cargo 200" when the idea reached some sort of pinnacle. Yet, despite the seeming similarity of the technique, there are important differences in the "Morphine". In both "Cargo 200" and "Morphine", the content of the songs formally does not coincide with the story of the film. However, in "Cargo 200", music is too optimistic, it represents a ceremonial, showcase reality. It is intended for collective perception and is broadcasted in a centralized way, against the will of its listeners. In "Morphine", most of the music is filled with desperate pain, it is characterized by confession and piercing sincerity of feelings (although not without a touch of genre conventions). Moreover, the sound of music depends on the will of a person wishing to listen to it at a given moment. So, the point is that in "Morphine" Balabanov is much more lenient on pop music than in "Cargo 200". Music is no longer a partner in crime, but rather an irreplaceable painkiller for the violence.

In addition, due to the historical distance, the idea that pop music is a kind of "the rmometer" of its era is embodied. Meanwhile, it is not a literal transcription of this or that historical context or events; it rather becomes inseparable from the epoch, proving to be one of the best ways of preserving and transmitting the atmosphere of the past time. 


\section{REFERENCES}

[1] E.D. Uvarova, How people had fun in Russian capitals. St. Petersburg: Aleteya, 2004, p. 250

[2] L.I.Levin, E.D.Uvarova,Household and applied music // History of Russian music in 10 volumes. Moscow: Music. Volume 10б: $1890-$ 1917. Edited byL.Z. Korabelnikova and E.M.Levasheva, 2004, p. 781-782.

[3] Balabanov, M.Kuvshinova, St. Petersburg: Book workshops, 2013,p. 13.

[4] L.I.Levin, E.D.Uvarova, Household and applied music // History of Russian music in 10 volumes. Moscow: Music. Volume 10б: $1890-$ 1917. Edited by L.Z. Korabelnikova and E.M.Levasheva, 2004,p. 788-789.

[5] V.G. Babenko,Aleksandr Vertinsky the artist. Biography. Reflexion. Sverdlovsk: 1989,p. 15.

[6] D.Dondurey,S. Tyrkin,"Morphine" in the context of A. Balabanov's work // Cinema art, No. 4, 2009. URL: https://www.kinoart.ru/archive/2009/04/n4-article3.Date of request 08.08.2018

[7] P.H. White, Director Balabanov's bricolage. Nizhniy Novgorod: DEOM, 2016,p. 16. 